\title{
The Borderline between Simultaneous Reverse \& Normal Initiation (SR\&NI) and Initiators for Continuous Activator Regeneration (ICAR) ATRP
}

Pawel Krys ${ }^{\dagger}$, Hendrik Schroeder ${ }^{\ddagger}$, Johannes Buback ${ }^{\dagger}$, Michael Buback ${ }^{\ddagger}$, Krzysztof Matyjaszewski ${ }^{\dagger} *$

${ }^{\dagger}$ Center for Macromolecular Engineering, Department of Chemistry, Carnegie Mellon

University, 4400 Fifth Avenue, Pittsburgh, Pennsylvania 15213

$\ddagger$ Institut für Physikalische Chemie, Georg-August-Universität Göttingen, Tammannstraße 6, D-

37077 Göttingen, Germany

* Corresponding author

Email:km3b@andrew.cmu.edu 
Table S1. Rate coefficients used for modeling of ICAR ATRP and SR\&NI ATRP of MA*

\begin{tabular}{ccc}
\hline $\begin{array}{c}\text { Rate } \\
\text { Coefficient }\end{array}$ & $k\left(\mathrm{M}^{-1} \mathrm{~s}^{-1}\right)$ & ref \\
\hline$k_{\text {deact }}$ & $1.0 \times 10^{7}$ & 1 \\
$k_{\mathrm{t}}^{1,1}$ & $1.0 \times 10^{9}$ & 2 \\
$k_{\mathrm{tR}}$ & $1.0 \times 10^{8}$ & 3 \\
$k_{\mathrm{td}}$ & 0 & 4 \\
$k_{\mathrm{tc}}$ & $1.0 \times 10^{8}$ & 3
\end{tabular}

MA*: Here and in what follows MA* refers to a hypothetical monomer with the rate parameters of methyl acrylate but without undergoing backbiting to form midchain radicals.

Table 2. Parameter variation used for modeling of ICAR ATRP and SR\&NI ATRP of MA*

\begin{tabular}{|c|c|c|c|c|c|c|c|}
\hline $\begin{array}{c}T \\
\left({ }^{\circ} \mathrm{C}\right)\end{array}$ & $\begin{array}{l}k_{\mathrm{dc}}^{\lfloor\mathrm{a}]} \\
{\left[\mathrm{s}^{-1}\right]}\end{array}$ & $\begin{array}{c}k_{\mathrm{p}}^{[\mathrm{b}]} \\
{\left[\mathrm{M}^{-1} \mathrm{~s}^{-1}\right]}\end{array}$ & $\begin{array}{c}k_{\text {add,RX }}[\mathrm{c}] \\
{\left[\mathrm{M}^{-1} \mathrm{~s}^{-1}\right]}\end{array}$ & $\begin{array}{l}k_{\text {add,AIBN }}[\mathrm{d}] \\
{\left[\mathrm{M}^{-1} \mathrm{~s}^{-1}\right]}\end{array}$ & $\begin{array}{c}{\left[\mathrm{Cu}^{\mathrm{II}} \mathrm{X}_{2} / \mathrm{L}\right]_{0}} \\
{[\mathrm{mM}]}\end{array}$ & $\begin{array}{l}{\left[\mathrm{I}_{2}\right]_{0}} \\
{[\mathrm{mM}]}\end{array}$ & $\begin{array}{c}k_{\text {act }} \\
\left.\left[\mathrm{M}^{-1} \mathrm{~s}^{-1}\right]\right]\end{array}$ \\
\hline 45 & $1.0 \times 10^{-6}$ & $2.45 \times 10^{4}$ & $2.73 \times 10^{4}$ & $5.27 \times 10^{2}$ & 20 & 10 & $1.0 \times 10^{-3}$ \\
\hline 60 & $1.0 \times 10^{-5}$ & $3.31 \times 10^{4}$ & $3.91 \times 10^{4}$ & $8.65 \times 10^{2}$ & 10 & 5 & $1.0 \times 10^{-2}$ \\
\hline 65 & $2.0 \times 10^{-5}$ & $3.63 \times 10^{4}$ & $4.37 \times 10^{4}$ & $1.01 \times 10^{3}$ & 5 & 2.5 & $1.0 \times 10^{-1}$ \\
\hline 70 & $3.0 \times 10^{-5}$ & $3.98 \times 10^{4}$ & $4.88 \times 10^{4}$ & $1.18 \times 10^{3}$ & 2 & 1 & $1.0 \times 10^{0}$ \\
\hline 80 & $1.0 \times 10^{-4}$ & $4.75 \times 10^{4}$ & $6.01 \times 10^{4}$ & $1.57 \times 10^{3}$ & 1 & 0.5 & $1.0 \times 10^{1}$ \\
\hline 85 & $3.0 \times 10^{-4}$ & $5.16 \times 10^{4}$ & $6.65 \times 10^{4}$ & $1.80 \times 10^{3}$ & 0.5 & 0.25 & $1.0 \times 10^{2}$ \\
\hline 95 & $1.0 \times 10^{-3}$ & $6.07 \times 10^{4}$ & $8.06 \times 10^{4}$ & $2.35 \times 10^{3}$ & & & $1.0 \times 10^{3}$ \\
\hline 105 & $3.0 \times 10^{-3}$ & $7.07 \times 10^{4}$ & $9.67 \times 10^{4}$ & $3.02 \times 10^{3}$ & & & $1.0 \times 10^{4}$ \\
\hline 115 & $1.0 \times 10^{-2}$ & $8.17 \times 10^{4}$ & $1.15 \times 10^{5}$ & $3.84 \times 10^{3}$ & & & \\
\hline 130 & $1.0 \times 10^{-1}$ & $1.00 \times 10^{5}$ & $1.47 \times 10^{5}$ & $5.36 \times 10^{3}$ & & & \\
\hline
\end{tabular}



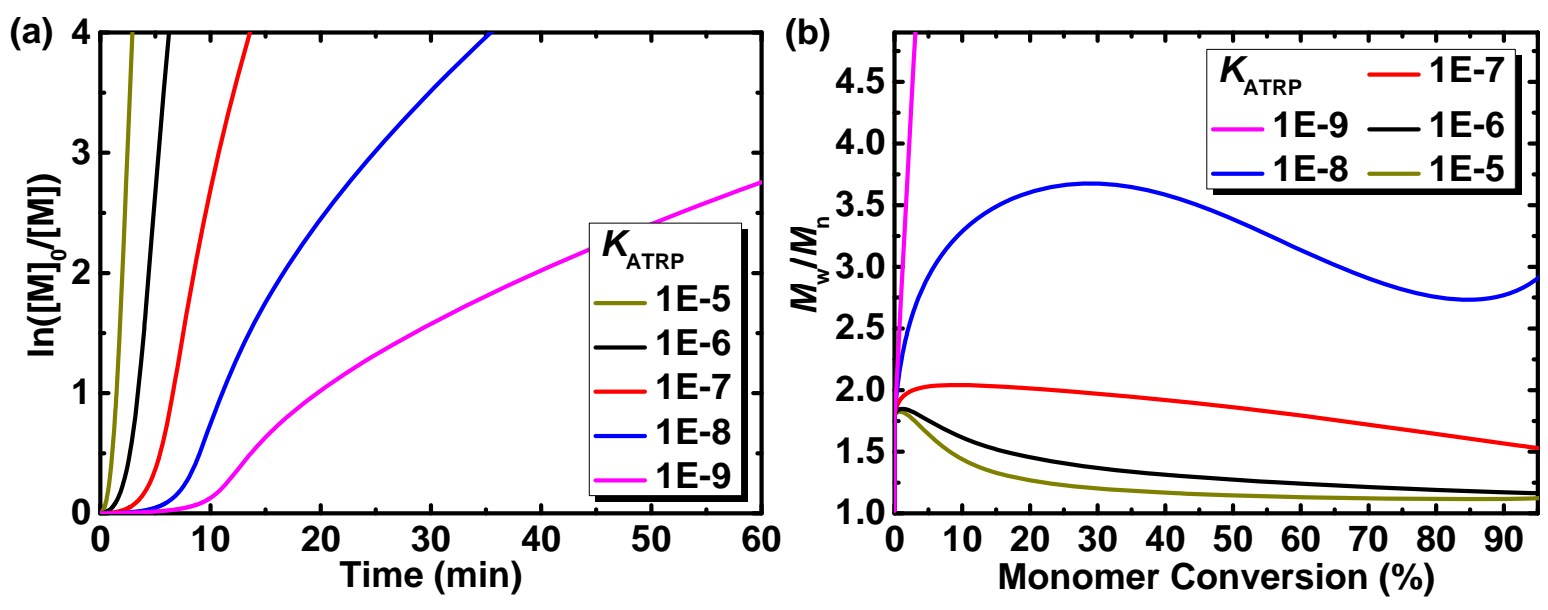

Figure S1. Simulation of (a) $\ln \left([\mathrm{M}]_{0} /[\mathrm{M}]\right)$ vs time traces, and (b) dispersity vs monomer conversion curves in SR\&NI ATRP at initial molar ratios of $\left[\mathrm{MA}^{*}\right]:[\mathrm{RX}]:\left[\mathrm{Cu}^{\mathrm{II}} \mathrm{X}_{2} / \mathrm{L}\right]:\left[\mathrm{I}_{2}\right]=$ 250:1:0.5:0.25, $\left[\mathrm{MA}^{*}\right]_{0}=5 \mathrm{M}$, estimated for a thermal initiator decomposition rate coefficient of $k_{\mathrm{dc}}=1 \times 10^{-2} \mathrm{~s}^{-1}\left(T=115{ }^{\circ} \mathrm{C}, k_{\mathrm{p}}=8.17 \times 10^{4} \mathrm{M}^{-1} \mathrm{~s}^{-1}\right)$ and various values of the ATRP equilibrium constant, $K_{\mathrm{ATRP}}$. The kinetic model is presented in Scheme 5. All other simulation parameters are listed in Table S1 and Table S2.
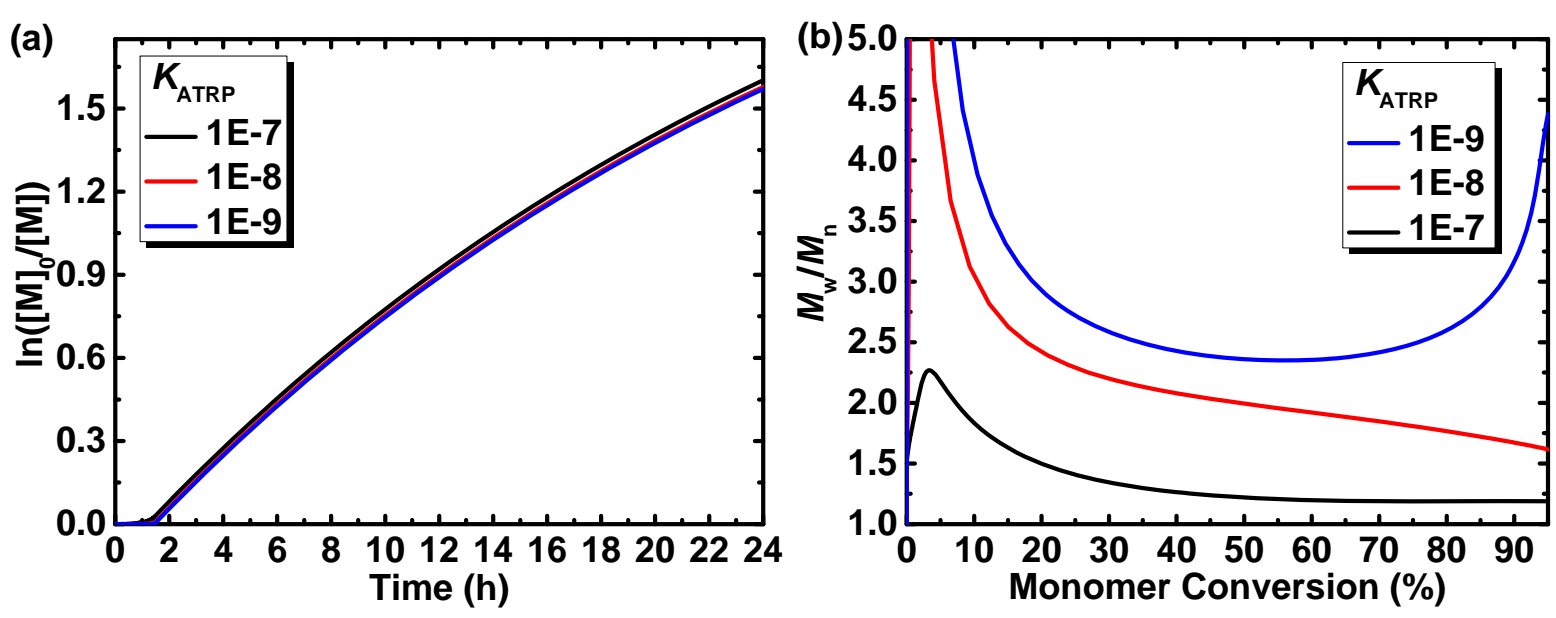

Figure S2. Simulation of (a) $\ln \left([\mathrm{M}]_{0} /[\mathrm{M}]\right)$ vs time traces, and (b) dispersity vs monomer conversion curves in ICAR ATRP at initial molar ratios of $[\mathrm{MMA}]:[\mathrm{RX}]:\left[\mathrm{Cu}^{\mathrm{II}} \mathrm{X}_{2} / \mathrm{L}\right]:\left[\mathrm{I}_{2}\right]=$ 250:1:0.025:0.125, $[\mathrm{MMA}]_{0}=5 \mathrm{M}$, estimated for a thermal initiator decomposition rate coefficient $k_{\mathrm{dc}}=2 \times 10^{-5} \mathrm{~s}^{-1}\left(T=65^{\circ} \mathrm{C}, k_{\mathrm{p}}=9.38 \times 10^{2} \mathrm{M}^{-1} \mathrm{~s}^{-1}\right)$ and various values of the ATRP equilibrium constant, $K_{\mathrm{ATRP}}$. The kinetic model is presented in Scheme 5. All other simulation parameters are listed in Table 1 and Table 2, except $k_{\mathrm{tc}}=3.33 \times 10^{7} \mathrm{M}^{-1} \mathrm{~s}^{-1}$ and $k_{\mathrm{td}}=6.66 \times 10^{7}$ $\mathrm{M}^{-1} \mathrm{~s}^{-1}$ 

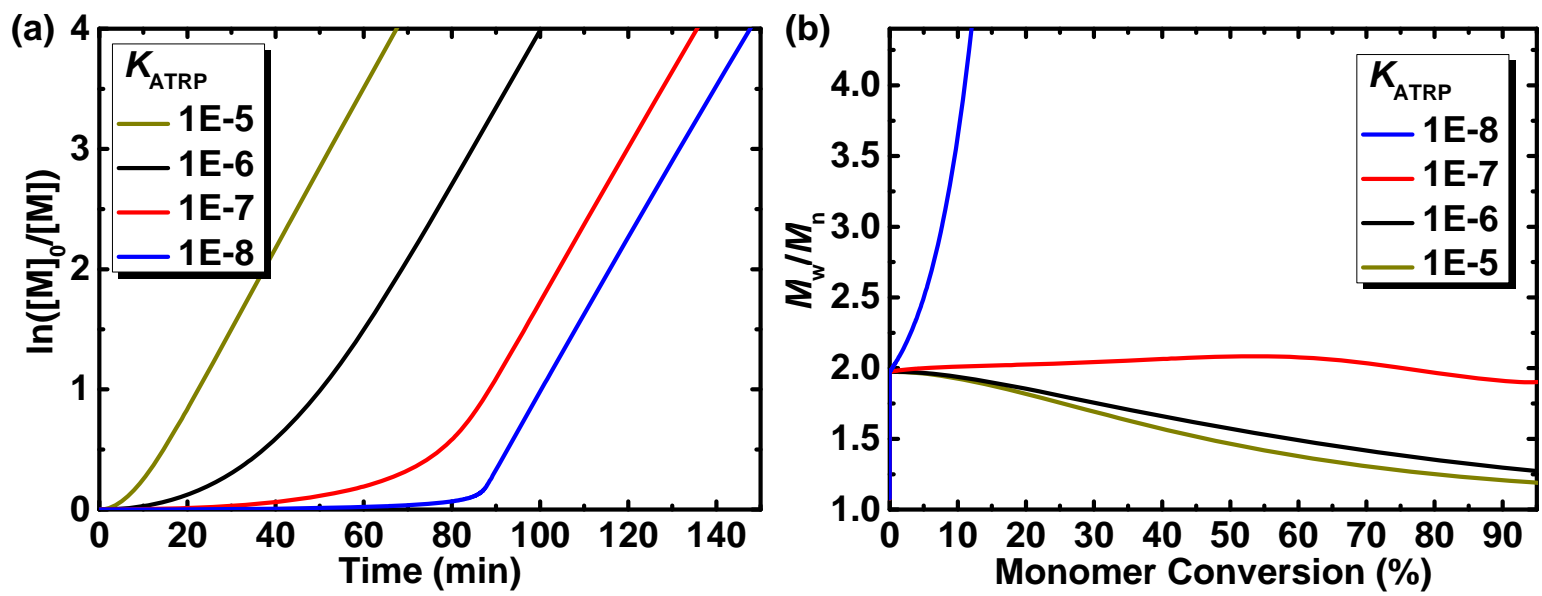

Figure S3. Simulation of (a) $\ln \left([\mathrm{M}]_{0} /[\mathrm{M}]\right)$ vs time traces, and (b) dispersity vs monomer conversion curves in ICAR ATRP at initial molar ratios of $\left[\mathrm{MA}^{*}\right]:[\mathrm{RX}]:\left[\mathrm{Cu}^{\mathrm{II}} \mathrm{X}_{2} / \mathrm{L}\right]:\left[\mathrm{I}_{2}\right]=$ 250:1:0.025:0.125, $\left[\mathrm{MA}^{*}\right]_{0}=5 \mathrm{M}$, estimated for a thermal initiator decomposition rate coefficient $k_{\mathrm{dc}}=2 \times 10^{-5} \mathrm{~s}^{-1}\left(T=65^{\circ} \mathrm{C}, k_{\mathrm{p}}=3.63 \times 10^{4} \mathrm{M}^{-1} \mathrm{~s}^{-1}\right)$ and various values of the ATRP equilibrium constant, $K_{\text {ATRP. }}$. The kinetic model is presented in Scheme 5. All other simulation parameters are listed in Table S1 and Table S2.
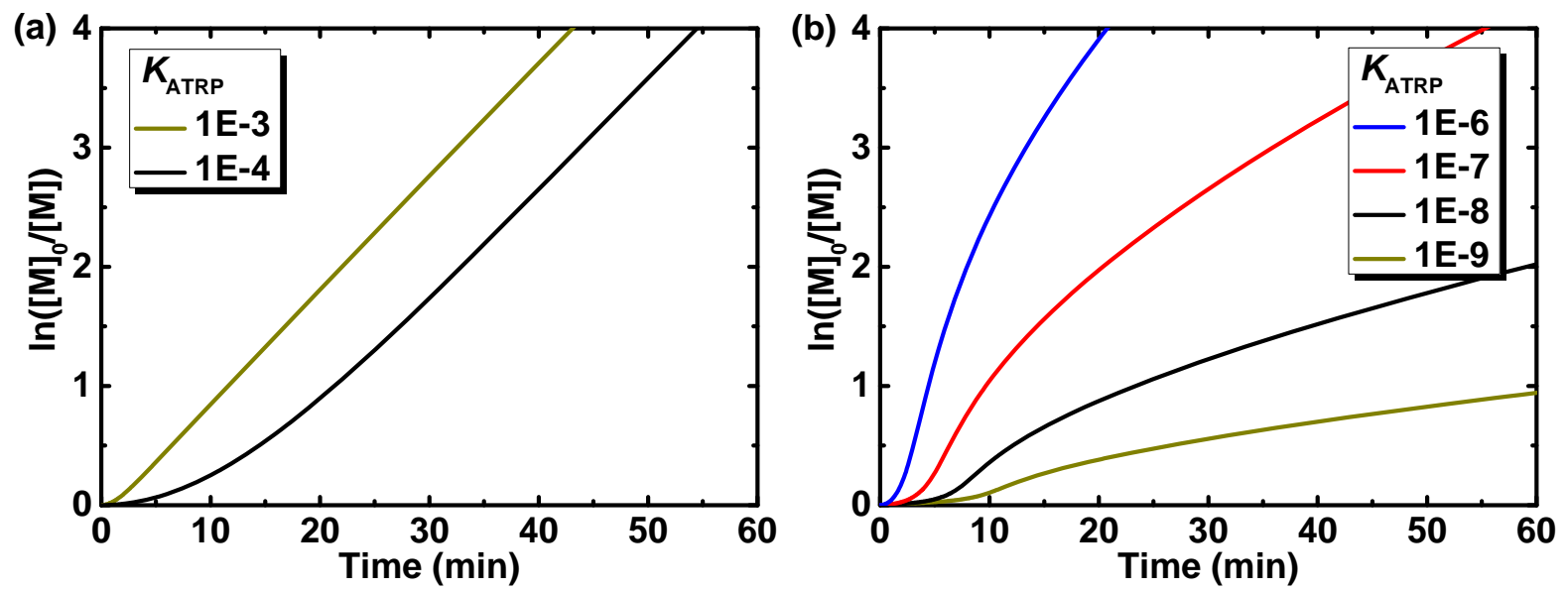

Figure S4. Plots of $\ln \left([\mathrm{M}]_{0} /[\mathrm{M}]\right)$ vs time in (a) an ICAR ATRP at a high $\mathrm{Cu}$ concentration and initial molar ratios of $\left[\mathrm{MA}^{*}\right]:[\mathrm{RX}]:\left[\mathrm{Cu}^{\mathrm{II}} \mathrm{X}_{2} / \mathrm{L}\right]:\left[\mathrm{I}_{2}\right]=250: 1: 0.5: 0.25,\left[\mathrm{MA}^{*}\right]_{0}=5 \mathrm{M}$, with a radical initiator decomposition rate coefficient of $k_{\mathrm{dc}}=2 \times 10^{-5} \mathrm{~s}^{-1}\left(T=65^{\circ} \mathrm{C}, k_{\mathrm{p}}=3.63 \times 10^{4} \mathrm{M}^{-1} \mathrm{~s}^{-1}\right)$ for various activation rate coefficients $k_{\mathrm{a}}$, and (b) SR\&NI ATRP at low $\mathrm{Cu}$ concentration and initial molar ratios of $\left[\mathrm{MA}^{*}\right]:[\mathrm{RX}]:\left[\mathrm{Cu}^{\mathrm{II}} \mathrm{X}_{2} / \mathrm{L}\right]:\left[\mathrm{I}_{2}\right]=250: 1: 0.025: 0.0125,\left[\mathrm{MA}^{*}\right]_{0}=5 \mathrm{M}$, with a radical initiator decomposition rate coefficient $k_{\mathrm{dc}}=1 \times 10^{-2} \mathrm{~s}^{-1}\left(T=115^{\circ} \mathrm{C}, k_{\mathrm{p}}=8.17 \times 10^{4} \mathrm{M}^{-1}\right.$ $\mathrm{s}^{-1}$ ) and various activation rate coefficients $k_{\mathrm{a}}$. The kinetic model is presented on Scheme 5. All other simulation parameters are listed in Table S1 and Table S2. 

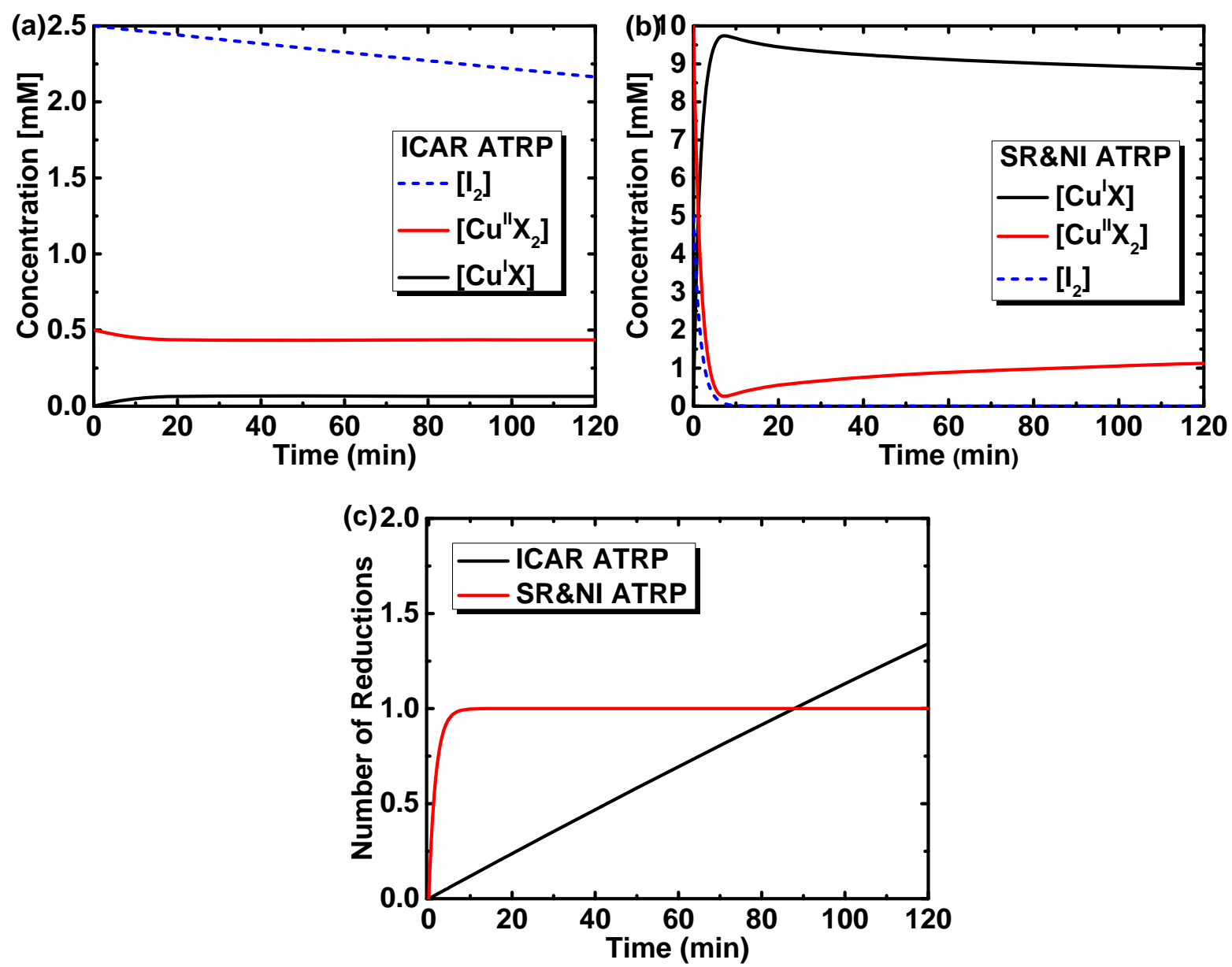

Figure S5. Simulated $\mathrm{Cu}^{\mathrm{II}}, \mathrm{Cu}^{\mathrm{I}}$ and $\mathrm{I}_{2}$ concentration vs time curves for (a) ICAR ATRP at initial molar ratios of $\left[\mathrm{MA}^{*}\right]:[\mathrm{RX}]:\left[\mathrm{Cu}^{\mathrm{II}} \mathrm{X}_{2} / \mathrm{L}\right]:\left[\mathrm{I}_{2}\right]=250: 1: 0.025: 0.125,\left[\mathrm{MA}^{*}\right]_{0}=5 \mathrm{M}$, for a thermal initiator decomposition rate coefficient of $k_{\mathrm{dc}}=2 \times 10^{-5} \mathrm{~s}^{-1}\left(T=65{ }^{\circ} \mathrm{C}, k_{\mathrm{p}}=3.63 \times 10^{4} \mathrm{M}^{-1} \mathrm{~s}^{-1}\right)$ and an activation rate coefficient of $k_{\mathrm{a}}=1 \times 10^{2} \mathrm{M}^{-1} \mathrm{~s}^{-1}$, (b) SR\&NI ATRP at initial molar ratios of $\left[\mathrm{MA}^{*}\right]:[\mathrm{RX}]:\left[\mathrm{Cu}^{\mathrm{II}} \mathrm{X}_{2} / \mathrm{L}\right]:\left[\mathrm{I}_{2}\right]=250: 1: 0.5: 0.25,\left[\mathrm{MA}^{*}\right]_{0}=5 \mathrm{M}$, with a thermal initiator decomposition rate coefficient of $k_{\mathrm{dc}}=1 \times 10^{-2} \mathrm{~s}^{-1}\left(T=115^{\circ} \mathrm{C}, k_{\mathrm{p}}=8.17 \times 10^{4} \mathrm{M}^{-1} \mathrm{~s}^{-1}\right)$ and an activation rate coefficient of $k_{\mathrm{a}}=1 \mathrm{M}^{-1} \mathrm{~s}^{-1}$. Shown in (c) is the calculated number of $\mathrm{Cu}^{\mathrm{II}}$ reductions for both reactions. The kinetic model is presented on Scheme 5. All other simulation parameters are listed in Table S1 and Table S2. 


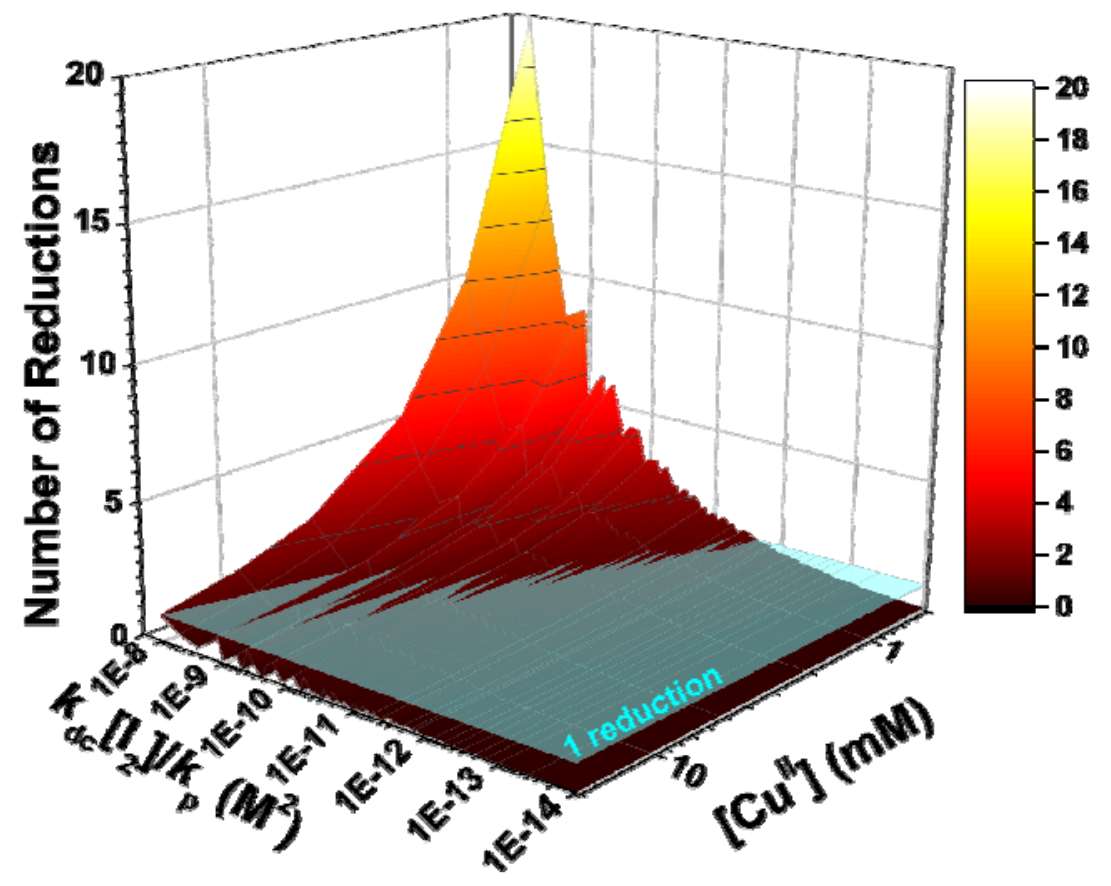

Figure S6. Number of $\mathrm{Cu}^{\text {II }}$ reductions calculated from Equation 5 at $90 \%$ monomer conversion as a function of $\left[\mathrm{Cu}^{\mathrm{II}}\right]$ and of the ratio $k_{\mathrm{dc}}\left[\mathrm{I}_{2}\right] / k_{\mathrm{p}}$. $\left[\mathrm{MA}^{*}\right]:[\mathrm{RX}]=250: 1$, [MA* $]_{0}=5 \mathrm{M}$, activation rate coefficient $k_{\mathrm{a}}=1 \times 10^{1} \mathrm{M}^{-1} \mathrm{~s}^{-1}$. The kinetic model is presented in Scheme 5. All other simulation parameters are listed in Table S1 and Table S2.
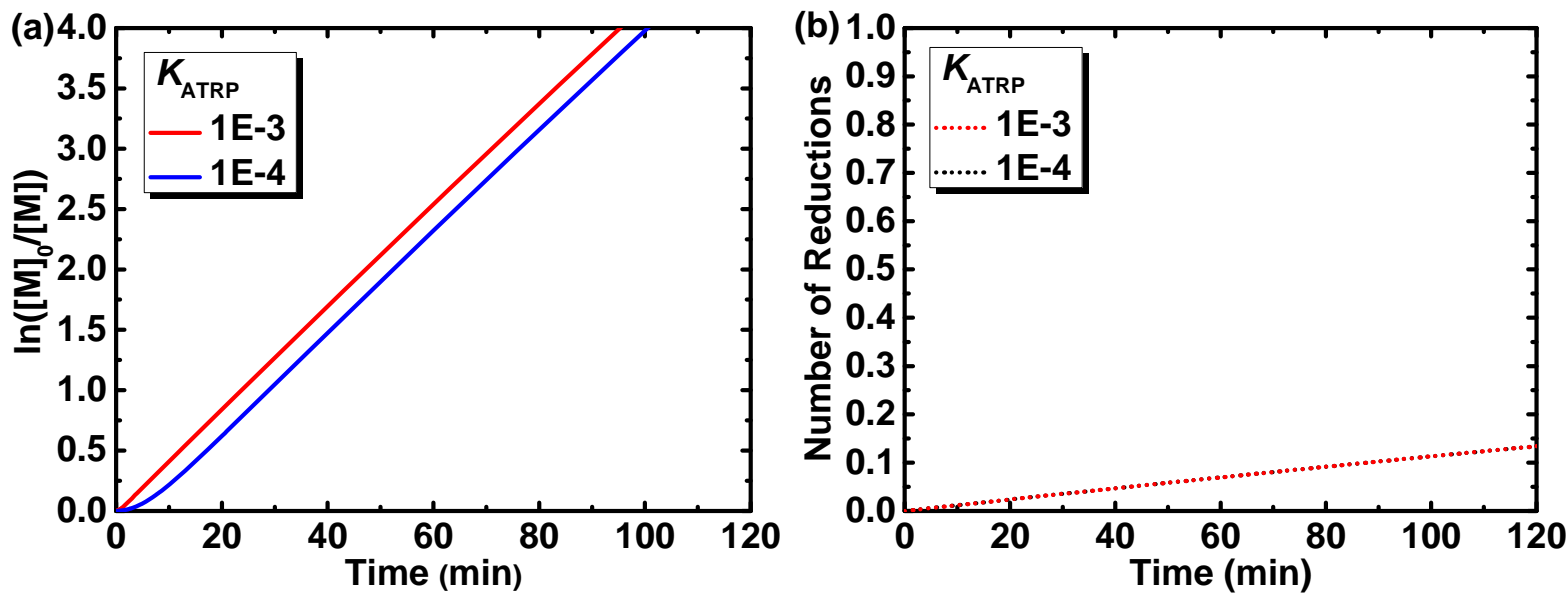

Figure S7. (a) Simulated $\ln \left([\mathrm{M}]_{0} /[\mathrm{M}]\right)$ vs time curves, and (b) calculated number of reductions for ICAR ATRP simulated with initial molar ratios of $\left[\mathrm{MA}^{*}\right]:[\mathrm{RX}]:\left[\mathrm{Cu}^{\mathrm{II}} \mathrm{X}_{2} / \mathrm{L}\right]:\left[\mathrm{I}_{2}\right]=$ 250:1:0.1:0.05, $\left[\mathrm{MA}^{*}\right]_{0}=5 \mathrm{M}$, with radical initiator decomposition rate coefficient of $k_{\mathrm{dc}}=2 \times$ $10^{-5} \mathrm{~s}^{-1}\left(T=65^{\circ} \mathrm{C}, k_{\mathrm{p}}=3.63 \times 10^{4} \mathrm{M}^{-1} \mathrm{~s}^{-1}\right)$ and varied activation rate coefficients, $k_{\mathrm{a}}$. The kinetic model is presented on Scheme 5. All other simulation parameters are listed in Table S1 and Table S2. 


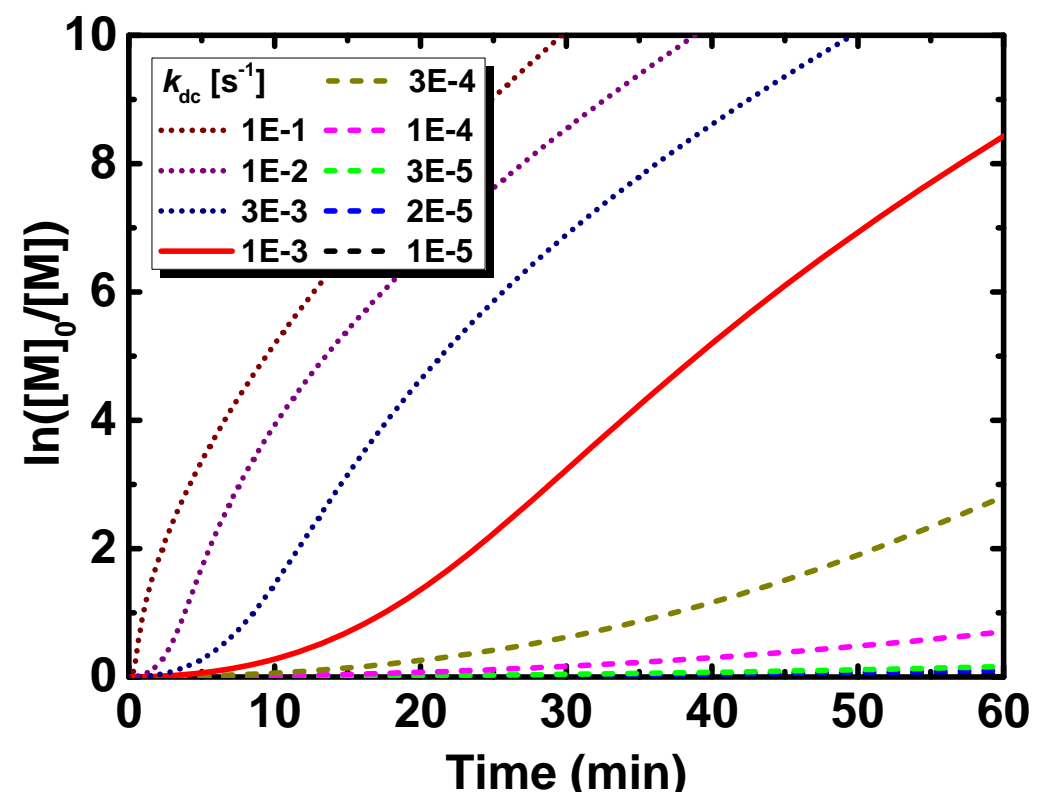

Figure S8. Simulated $\ln \left([\mathrm{M}]_{0} /[\mathrm{M}]\right)$ vs time curves for initial molar ratios of $\left[\mathrm{MA}^{*}\right]:[\mathrm{RX}]:\left[\mathrm{Cu}^{\mathrm{II}} \mathrm{X}_{2} / \mathrm{L}\right]:\left[\mathrm{I}_{2}\right]=250: 1: 0.1: 0.05,\left[\mathrm{MA}^{*}\right]_{0}=5 \mathrm{M}$, for an activation rate coefficient of $k_{\mathrm{a}}=1 \times 10^{1} \mathrm{M}^{-1} \mathrm{~s}^{-1}$ and various initiator decomposition rate coefficients $k_{\mathrm{dc}}$. The kinetic model is presented on Scheme 5. All other simulation parameters are listed in Table S1 and Table S2.

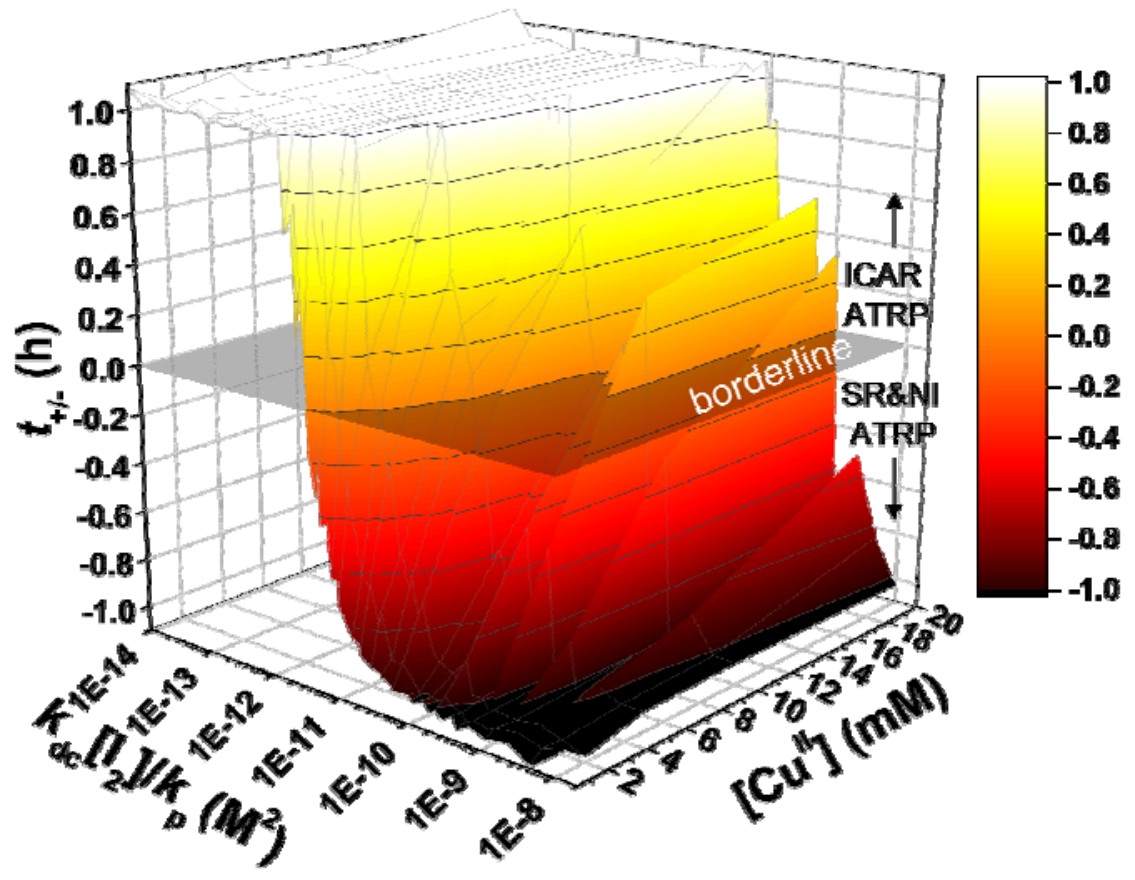

Figure S9. Concavity of the $\ln \left([\mathrm{M}]_{0} /[\mathrm{M}]\right)$ profiles described by the difference between the time during which the curve was concave up and concave down $\left(t_{++-}\right)$as a function of $\left[\mathrm{Cu}^{\mathrm{II}}\right]$ and of the ratio $k_{\mathrm{dc}}\left[\mathrm{I}_{2}\right] / k_{\mathrm{p}}$. [MA*]:[RX] $=250: 1,\left[\mathrm{MA}^{*}\right]_{0}=5 \mathrm{M}$, activation rate coefficient $k_{\mathrm{a}}=1 \times 10^{1} \mathrm{M}^{-1}$ 
$\mathrm{s}^{-1}$. The kinetic model is presented in Scheme 5. All other simulation parameters are listed in Table S1 and Table S2.

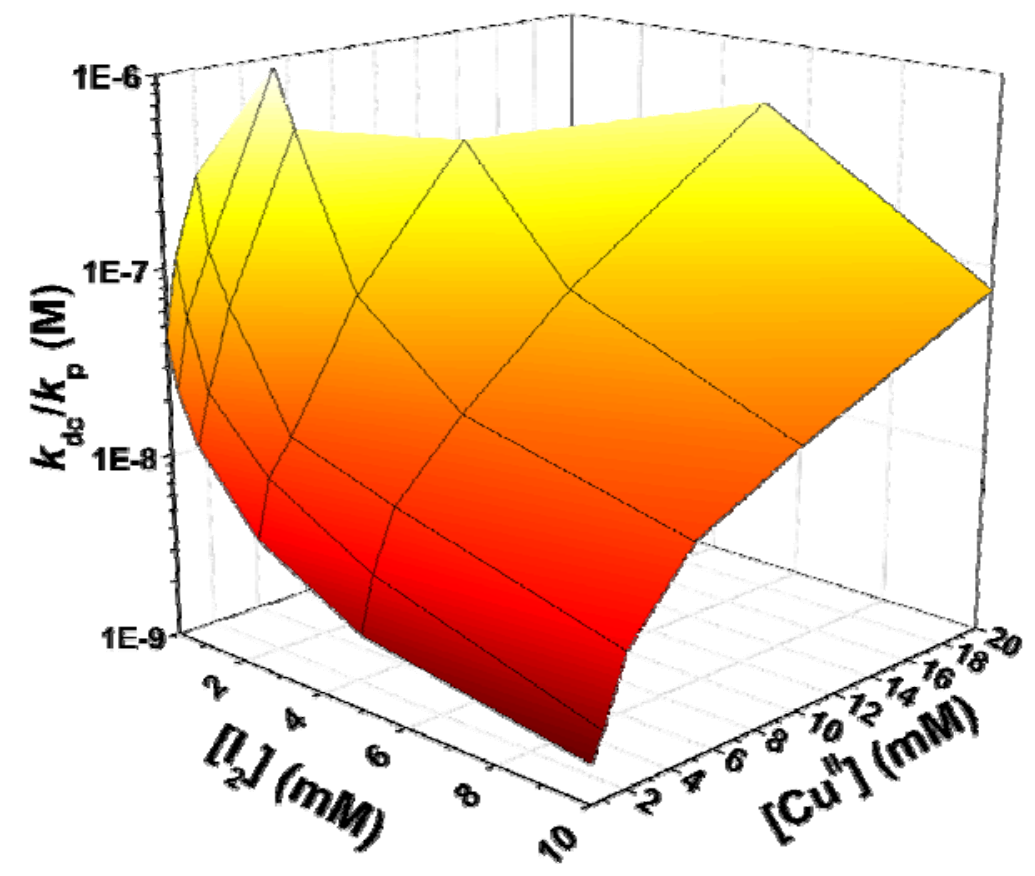

Figure S10. Simulated ratio of thermal initiator decomposition rate coefficient and propagation rate coefficient $\left(k_{\mathrm{dc}} / k_{\mathrm{p}}\right)$ at the borderline between ICAR ATRP and SR\&NI ATRP as a function of $\left[\mathrm{Cu}^{\mathrm{II}}\right]$ and $\left[\mathrm{I}_{2}\right] .\left[\mathrm{MA}^{*}\right]:[\mathrm{RX}]=250: 1,\left[\mathrm{MA}^{*}\right]_{0}=5 \mathrm{M}$, activation rate coefficient $k_{\mathrm{a}}=1 \times 10^{1}$ $\mathrm{M}^{-1} \mathrm{~s}^{-1}$. The kinetic model is presented in Scheme 5. All other simulation parameters are given in Table 1 and Table 2.

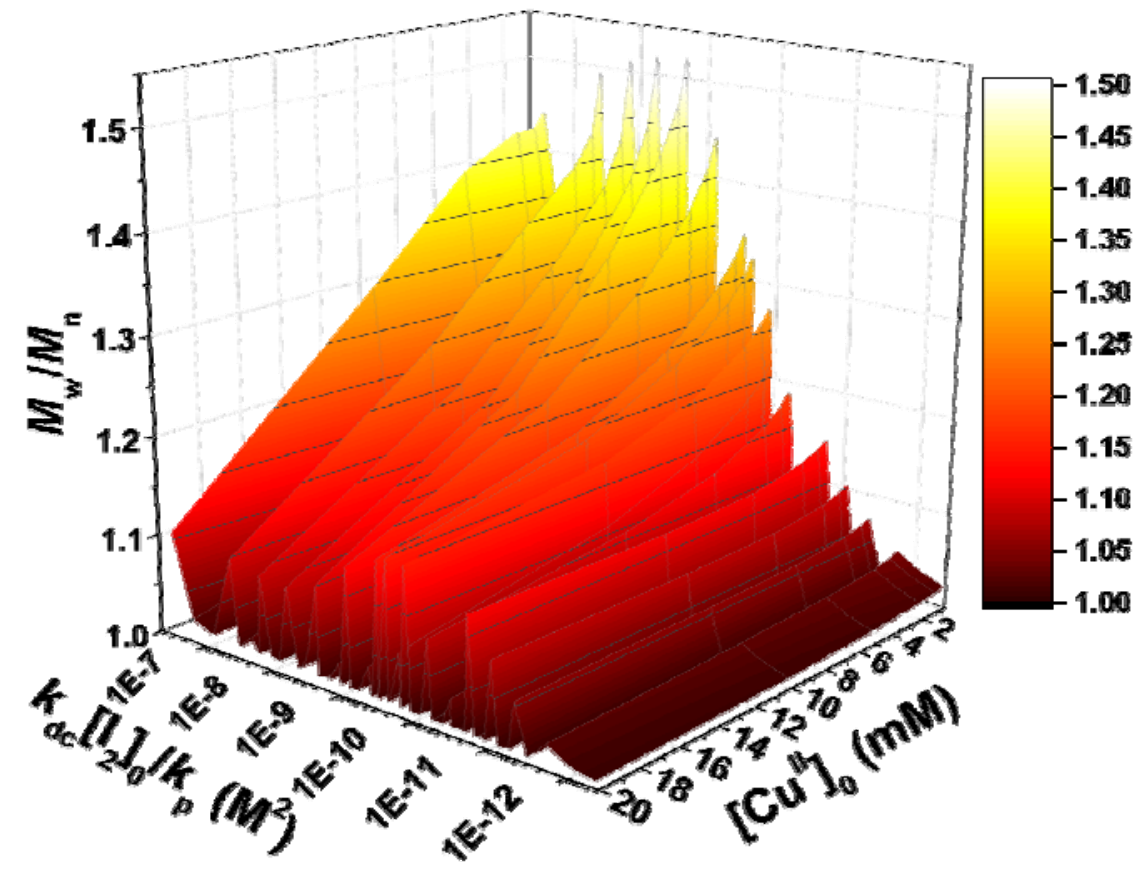

Figure S11. Simulated $M_{\mathrm{w}} / M_{\mathrm{n}}$ at $90 \%$ monomer conversion as a function of $\left[\mathrm{Cu}^{\mathrm{II}}\right]_{0}$ and of the ratio $k_{\mathrm{dc}}\left[\mathrm{I}_{2}\right]_{0} / k_{\mathrm{p}}$. [MMA]:[RX] $=250: 1,[\mathrm{MMA}]_{0}=5 \mathrm{M}$, activation rate coefficient $k_{\mathrm{a}}=1 \times 10^{1}$ 
$\mathrm{M}^{-1} \mathrm{~s}^{-1}$. The kinetic model is presented in Scheme 5. All other simulation parameters are listed in Table 1 and Table 2.

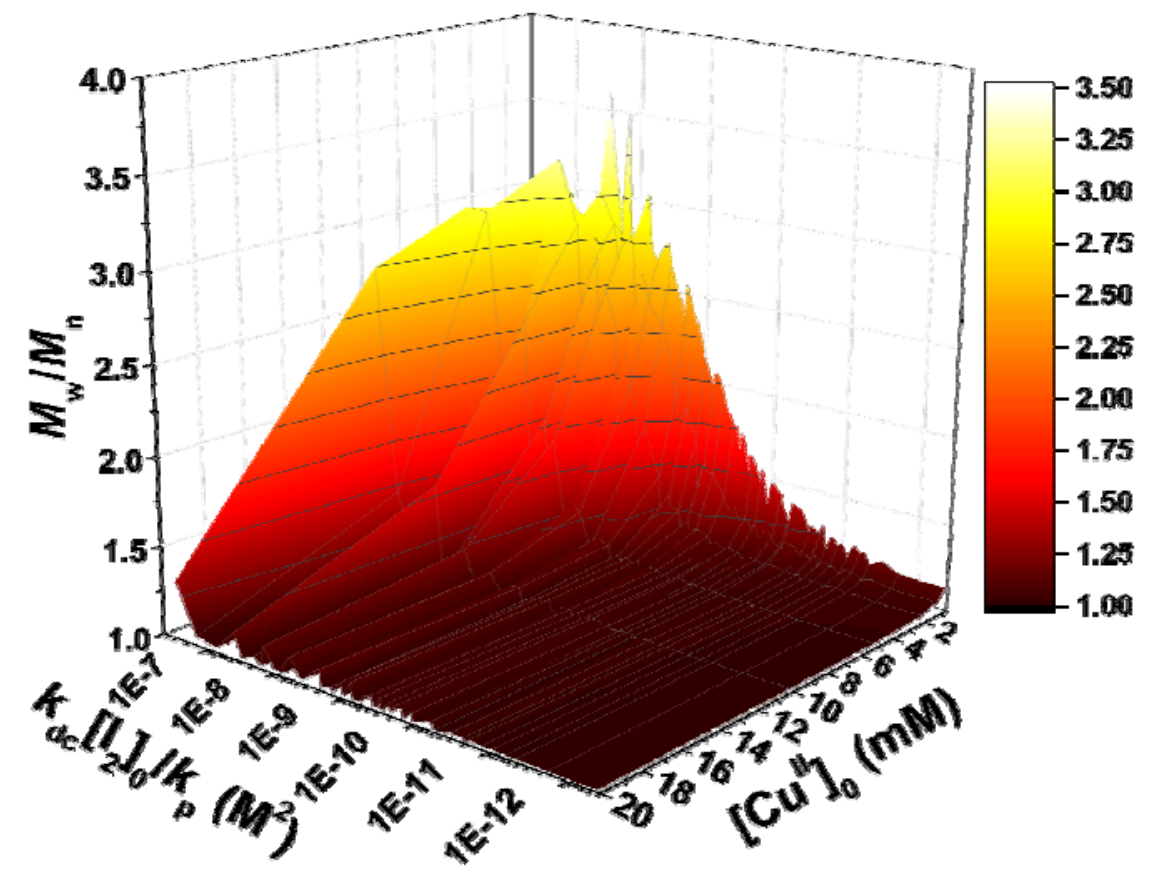

Figure S12. Simulated $M_{\mathrm{w}} / M_{\mathrm{n}}$ at $90 \%$ monomer conversion as a function of $\left[\mathrm{Cu}^{\mathrm{II}}\right]_{0}$ and of the ratio $k_{\mathrm{dc}}\left[\mathrm{I}_{2}\right]_{0} / k_{\mathrm{p}}$. [MA*]:[RX] $=250: 1,\left[\mathrm{MA}^{*}\right]_{0}=5 \mathrm{M}$, activation rate coefficient $k_{\mathrm{a}}=1 \times 10^{1} \mathrm{M}^{-1}$ $\mathrm{s}^{-1}$. The kinetic model is presented in Scheme 5. All other simulation parameters are listed in Table S1 and Table S2. 


\section{References:}

(1) Tang, W.; Kwak, Y.; Braunecker, W.; Tsarevsky, N. V.; Coote, M. L.; Matyjaszewski, K., Understanding Atom Transfer Radical Polymerization: Effect of Ligand and Initiator Structures on the Equilibrium Constants. J. Am. Chem. Soc. 2008, 130, 10702-10713.

(2) Braunecker, W. A.; Tsarevsky, N. V.; Gennaro, A.; Matyjaszewski, K., Thermodynamic Components of the Atom Transfer Radical Polymerization Equilibrium: Quantifying Solvent Effects. Macromolecules 2009, 42, 6348-6360.

(3) Buback, M.; Kuelpmann, A.; Kurz, C., Termination Kinetics of Methyl Acrylate and Dodecyl Acrylate Free-Radical Homopolymerizations up to High Pressure. Macromol. Chem. Phys. 2002, 203, 1065-1070.

(4) Moad, G.; Solomon, D. H., The chemistry of free radical polymerization. 2nd Ed. ed.; Elsevier: Amsterdam, 2006.

(5) Brandrup, J.; Immergut, E. H.; Grulke, E. A.; Abe, A.; Bloch, D. R., Polymer handbook. Wiley New York: 1999; Vol. 89.

(6) Buback, M.; Kurz, C. H.; Schmaltz, C., Pressure dependence of propagation rate coefficients in free-radical homopolymerizations of methyl acrylate and dodecyl acrylate. Macromol. Chem. Phys. 1998, 199, 1721-1727.

(7) Knühl, B.; Marque, S.; Fischer, H., Absolute Rate Constants for the Addition of the 1-(tertButoxy)carbonylethyl Radical to Alkenes in Solution. Helvetica Chimica Acta 2001, 84, 22902300.

(8) Fischer, H.; Radom, L., Factors Controlling the Addition of Carbon-Centered Radicals to Alkenes-An Experimental and Theoretical Perspective. Angew. Chem., Int. Ed. 2001, 40, 13401371. 